\title{
Cytoplasmic signaling in the control of mitochondrial uproar? Martin Hermann ${ }^{1}$, Andrey Kuznetsov'2, Manuel Maglione ${ }^{2,3}$, Julija Smigelskaite ${ }^{2}$, Raimund Margreiter ${ }^{2,3}$ and Jakob Troppmair*2
}

Address: ${ }^{1}$ KMT Laboratory, Innsbruck Medical University (IMU), Innrain 66, A-6020 Innsbruck, Austria, ${ }^{2}$ Daniel Swarovski Research Laboratory, Innsbruck Medical University (IMU), Innrain 66, A-6020 Innsbruck, Austria and ${ }^{3}$ Center of Operative Medicine, Department of Visceral, Transplant and Thoracic Surgery, Anichstrasse 35, Innsbruck Medical University, A-6020 Innsbruck, Austria

Email: Martin Hermann - martin.hermann@uki.at; Andrey Kuznetsov - andrey.kuznetsov@uki.at; Manuel Maglione - manuel.maglione@imed.ac.at; Julija Smigelskaite - julijasmigelskaite@yahoo.com; Raimund Margreiter - raimund.margreiter@i-med.ac.at; Jakob Troppmair* - jakob.troppmair@i-med.ac.at

* Corresponding author

Published: 19 August 2008

Cell Communication and Signaling 2008, 6:4 doi:10.1186/1478-8IIX-6-4

This article is available from: http://www.biosignaling.com/content/6/1/4

entral Ltd.

This is an Open Access article distributed under the terms of the Creative Commons Attribution License (http://creativecommons.org/licenses/by/2.0), which permits unrestricted use, distribution, and reproduction in any medium, provided the original work is properly cited.

\begin{abstract}
The concept of a pre-emptive strike as a good means to prevent greater harm may be frequently over-stressed in daily life. However, biological systems in a homeostatic balance are prepared to withstand a certain degree of hostile fire by rather passive means. This also applies to the maintenance of cell survival, where a plethora of protective proteins provide safeguard against erroneous activation of death pathways. Apart from these mechanisms active processes are also essential for the maintenance of cellular homeostasis, commonly referred to as survival signaling. Frequently their targets may be mitochondrial, assuring organelle integrity, which is essential for continued energy production and survival. Transient or permanent failures in these cellular defense strategies result in pathophysiological conditions, which manifest themselves e.g. as cancer or ischemia/reperfusion-associated organ damage.
\end{abstract}

\section{Review}

During times of peace cells are dependent on a balanced crosstalk with their surrounding environment. Survival and proper functioning not only require physical contact with their neighbors, but also depend on a plethora of soluble factors such as hormones or growth factors. The full spectrum of possible cell fates is governed by these mutual and highly dynamic interactions. In the extreme case a dissonance in this "orchestra of life" leads to cell death. However, in order for this to happen a variety of safeguard mechanisms have to fail and cells are normally sufficiently guarded against these threats.

Subversion of intracellular control mechanisms is linked to many pathophysiological conditions. In particular, cancer cells are geared towards cellular autonomy, which is achieved through aberrant activation of intracellular signaling processes. As a consequence these cells are in a preemptive way programmed to withstand hostile conditions and to thrive in a growth and survival limiting environment. Thus cancer provided a useful model for the delineation of mechanisms used to counter potential assaults. Its analysis taught us that tumors in a unique way are equipped to withstand limitation in life supporting oxygen or nutrient supply. Many of the genetic defects found in tumors reside in signaling cascades or proteins, supporting the key role of aberrant signaling in this. However, protective mechanisms also can be triggered in a more rapid and transient fashion. During transplantation organs are temporarily deprived of oxygen, nutrients and 
growth factors (ischemia). A decrease in myocardial oxygen delivery initially results in decreased contractile activity and oxygen consumption, a phenomenon termed hibernating myocardium [1]. Prolonged hypoxia may also reduce ATP demand by down-regulating protein synthesis [2]. Restoration of blood flow (reperfusion) corrects these deficits but at the same time initiates a detrimental cascade, which in the end can lead to irreversible damage of the affected organ. During reperfusion organs also respond with the activation of intracellular signaling pathways. Some of these signaling activities are clearly linked to the cell death induction, while others may be involved in the elicitation of a protective response. Through repeated short ischemic intervals which do not cause irreversible damage ("pre-conditioning"), cells may actually learn to cope with conditions, which are normally lifethreatening. Also this defense mechanism is operated by intracellular signaling pathways [3]. Therefore, understanding the role of signaling in ischemia-reperfusion induced injury (IRI) holds the potential for the development of novel therapeutic strategies for its prevention, perhaps even at a time point before other events like the production of reactive oxygen species (ROS), the perturbation of $\mathrm{Ca}^{2+}$ homeostasis or inflammatory responses occur, which will greatly amplify the damage. Mitochondria feature prominently in these processes as they are critical for the provision of energy and the assurance of cell survival. A coordinated cellular response will require crosstalk between mitochondria and their cellular environment. Cytoplasmic signaling pathways are increasingly recognized for their central role in relaying information to the mitochondria and in possibly controlling their function [4]. In this review we will present a current view of mitochondrial form and function, before we discuss the dealings of mitochondria with the cellular environment. Finally we will use the example of ischemia/ reperfusion-induced tissue damage to illustrate the cooperation of these players and to show up possible therapeutic implications.

\section{From form to function: Mitochondria shaping up for performance}

The classical view of mitochondria as bean-shaped organelles has changed dramatically over the last years. Earlier studies shed light on the complexity of their internal organization [5], while most recently another feature of these organelles has attracted considerable interest, their highly dynamic behavior [6]. Through fission and fusion mitochondrial morphology can change from small spheres or short rods to long tubules forming large network-like structures within the same cell. Another level of complexity is added through their high motility. While the highest velocity was found in neurons, mitochondrial movement could be shown in various other cell systems such as HL-1 cells, cultured fibroblasts, budding yeast, etc.
[7-11]. Mitochondria can be actively transported in cells and may have defined tissue-specific subcellular distributions. In neurons, for example, they are translocated to regions with high energy and $\mathrm{Ca}^{2+}$ buffering demands, such as active growth cones, pre- and post-synaptic sites. In addition, they often pause at sites where no mitochondria are present, resulting in an uniform axonal mitochondrial distribution. Mitochondria with high membrane potential preferentially migrate in the anterograde direction, whereas mitochondria with low membrane potential move in the retrograde direction. Therefore active mitochondria appear at distal regions with high energy demands, while impaired mitochondria are returned to the cell soma, possibly for repair or mitophagy. In addition, signaling molecules such as nerve growth factor (NGF) influence mitochondrial recruitment and retention [12].

Several studies have suggested that controlling mitochondrial shape through fusion and fission is also crucial for maintaining the functional properties of mitochondria [6]. The precise balance between these two opposing processes therefore might play a key role in mitochondrial and cellular function. More than ten years ago, the first molecular mediator of mitochondrial fusion was discovered in Drosophila melanogaster: Fusion factor fuzzy onions (Fzo), a mitochondrial outer membrane GTPase that is required for the fusion of mitochondria during spermatogenesis [13]. The two human Fzo homologues Mitofusin (Mfn) 1 and 2 also control mitochondrial morphology $[14,15]$. As a subset of mitochondria in Mfn1-deficient cells was shown to lose their membrane potential, mitochondrial fusion seems to allow cooperation between mitochondria, thereby protecting mitochondria from respiratory dysfunction [15]. Also Mfn2 ablation experiments have documented a reduced mitochondrial oxidation and membrane potential as well as a repression of nuclearencoded subunits of OXPHOS complexes [16]. In mammals, mitochondrial fission requires the recruitment of cytosolic dynamin-related protein (DRP1) [17]. Posttranslational modifications regulate its function in mitochondrial fission. The ubiquitin ligase of the mitochondrial outer membrane, termed membrane-associated RING-CH (MARCH)-V, a member of the transmembrane RING-finger protein family, has the ability to bind to Mfn2 and DRP1, to ubiquitinate DRP1 and to modify mitochondrial morphology. By regulating Mfn2 and Drp1 activities, MARCH-V controls mitochondrial morphology [18].

In addition, cellular stress influences mitochondrial fusion and fission: Thus DRP1 was also shown to be involved in apoptosis-associated mitochondrial fission. While under normal conditions DRP1 recycles between the cytoplasm and mitochondria, it shows a stable mem- 
brane association following the recruitment of BAX to the mitochondrial membrane but before the loss of mitochondrial membrane potential. During apoptosis, the biochemical properties of DRP1 are regulated via a BAX/ BAK-dependent stimulation of small ubiquitin-like modifier-1 conjugation to DRP1 [19]. Recent findings have demonstrated a key role of the proper regulation of mitochondrial dynamics for various cellular pathways, demonstrating also that defective mitochondrial behavior may affect human health. For example, several neurological diseases (e.g. Charcot-Marie-Tooth, CMT; autosomal dominant optic atrophy, DOA) are associated with mutations in proteins that control mitochondrial dynamics and morphology like mitofusin-2 and OPA1 [20,21].

\section{Breathing oxygen-producing ROS}

The change in earth's atmosphere from anoxic to our current conditions of approx. 21\% oxygen had on the one hand catastrophic effects on unicellular anaerobic life forms but on the other hand paved the way for new forms of life which managed to tame this highly reactive and due to its oxidizing properties potentially life-threatening molecule and made a renegade of it changing fronts from life threatening to life supporting [22]. The supply of ATP through oxidative phosphorylation, which couples the oxidation of metabolic substrates to the synthesis of ATP from ADP and inorganic phosphate takes place in the mitochondria, putative descendents of an ancient endosymbiotic event between an alpha-proteobacterium and an archean host $[23,24]$. Utilizing oxygen as the final electron acceptor in the aerobic metabolism of glucose as the primary source of energy increased the efficiency of ATP generation.

The mitochondrial respiratory chain transfers electrons to molecular oxygen, permanently producing ROS as a byproduct of oxidative phosphorylation. Depending on the conditions, a few percents of the oxygen consumed by mitochondria are reduced by a single free electron with formation of superoxide radical, which then can be converted to hydrogen peroxide (further mono-electron reduction of oxygen) by mitochondrial superoxide dismutase (SOD), which in turn can be scavenged by catalase reaction or converted to the very reactive hydroxyl radical in the presence of transition metals (e.g. $\mathrm{Fe}^{2+}$ ). Several reports have demonstrated that mitochondrial superoxide production is mostly a result of incomplete reduction of oxygen at sites of respiratory complexes I (NADH:ubiquinone oxidoreductase) and III (CoQ:cytochrome $c$ oxidoreductase) which therefore can be considered as main sources for mitochondrial ROS [25-29].

\section{Sensing cellular energy status}

Mitochondria are able to monitor their surrounding environment, including intracellular energy (ATP) levels, as well as oxygen, ROS, $\mathrm{Ca}^{2+}$ and the presence or absence of growth factors [4]. Moreover, mitochondria are well tailored to meet both the signaling and metabolic needs of the cell. It has been suggested that mitochondrial biogenesis (mitochondrial proliferation) and dynamics are strongly linked to the ability of mitochondria to sense energy status [7,30-33]. In muscles confronted with increased work load (training, endurance exercise) or pathological changes (mitochondrial diseases, genetic defects in respiratory complexes), the proliferation of mitochondria serves as an adaptational response to decreased energy levels [33]. In other cells like neurons, energy sensing mechanisms may also serve for the directorial transport of mitochondria to the cellular regions of higher energy demands [7]. One of the key enzymes for low-energy sensing is AMP activated protein kinase (AMPK) [34]. AMPK is an evolutionarily conserved enzyme which is allosterically activated by AMP (marker of low energy status). In addition, AMPK is strongly regulated by changes in phosphorylation state by upstream kinases and phosphatases [34-36]. This enzyme therefore is sensitive to increases in the cellular AMP/ATP ratio and can be activated by various metabolic stresses, such as ischemia, hypoxia, starvation (e.g. glucose deprivation), by metabolic inhibition (e.g. using analogs of energy substrates or simulated ischemia) or in response to increased exercise in muscles [31,37-40]. Stimuli for AMPK involve either processes that inhibit ATP production or accelerate ATP consumption. Active AMPK upregulates catabolic and suppresses anabolic pathways $[38,41]$. For example, AMPK may phosphorylate and thus inhibit enzymes of ATP consuming pathways like the formation of fatty acids, cholesterol and glycogen (e.g. acetyl-CoA-carboxylase, glycogen synthase, etc.), and also highly ATP consuming protein synthesis by eEF2K phosphorylation [42]. Moreover, active AMPK blocks cell growth and proliferation by suppression of the target of rapamycin (mTOR) pathway $[43,44]$ via direct phosphorylation of an upstream regulator of mTOR, tuberous sclerosis complex-2 (TSC2 or tuberin) [45]. This type of downregulation of mTOR signaling seems to be dominant over the positive effects of growth factors or amino acids. More recent data suggest two inhibitory effects of AMPK on mTOR. Activated AMPK may phosphorylate TSC2 at a site different from AKT, promoting its Rheb-GAP activity, and additionally it may phosphorylate raptor (regulatory associated protein of mTOR), also resulting in mTOR inhibition [46], leading to a suppression of protein synthesis and overall cellular ATP consumption. At the same time, AMPK activation in muscles could markedly stimulate glucose uptake by increased translocation of the glucose transporter GLUT4 to the plasma membrane [47] via phosphorylation of a downstream target of AMPK - AS160, a Rab GTPase-activating protein [48]. Besides, acute or chronic chemical activation of AMPK in muscles results also in elevated 
GLUT4 expression (with remarkable increase in GLUT4 mRNA levels) $[49,50]$. Therefore, through activation of both GLUT4 translocation and GLUT4 expression, activated AMPK stimulates glycolysis in muscles. In addition, activation of 6-phosphofructo-2 kinase (PFK) by AMPK also supports glycolytic ATP production. Furthermore, phosphorylation of acetyl-CoA carboxylase (ACC) by AMPK decreases malonyl-CoA levels [51], reducing inhibition of carnitine palmitoyl-CoA acyltransferase-1 (the enzyme responsible for transport of fatty acids into mitochondria), stimulating utilization of fatty acids and helping thus better mitochondrial ATP production. AMPK activation therefore serves to defend against energy deficiency via activation of glucose transport and oxidation of fatty acids [34,52-54]. Growing evidence [30,31] demonstrates that AMPK is also a critical regulator involved in initiating mitochondrial biogenesis through activation of the peroxisome proliferator activated receptor $\gamma$ coactivator $1 \alpha$ (PGC- $1 \alpha$ ) which is an important regulator of transcription of many genes involved in mitochondrial energy metabolism, mitochondrial physiology and oxidation of glucose and fatty acids [55]. Notably, AMPK also interferes with mitochondrially produced ROS and reactive nitrogen species (RNS), as well as with their scavengers: like vitamin E, N-acetylcysteine, the SOD-mimetic MnTBAP, or $\alpha$-Lipoic acid (powerful antioxidant and an essential cofactor for several mitochondrial enzymes) $[40,56,57]$.

Metabolic dysregulation is commonly observed under conditions of metabolic stress, e.g. cancer, ischemia/reperfusion. In tumors it may be an important contributor to the transformation process. Thus the frequently described switch to glycolysis which also persists under aerobic conditions ("Warburg effect") may in part be caused by direct effects of cancer protein signaling on the expression/activity of glycolytic enzymes [58-60]. The discovery of mutations in succinate dehydrogenase and fumarate hydratase, components of the tricarboxylic acid (TCA) cycle (also known as Krebs cycle), which connects cytosolic glucose metabolism to mitochondrial oxidative phosphorylation (OXPHOS), led to the demonstration of a tumor suppressor function for these proteins [61]. When these genes are mutated, succinate or fumarate, respectively, accumulate in mitochondria and pass to the cytosol resulting in the inhibition of prolyl hydroxylases (PHDs) and consecutive stabilization of transcription factor hypoxia-inducible factor $1 \alpha(\mathrm{HIF} 1 \alpha)$ under normoxic conditions [62] with important consequences for the expression of target genes required for tumor growth and metastasis. Finally, also mitochondrial DNA (mtDNA) may carry mutations which through impairment of OXPHOS, increased ROS production and increased proliferation contribute to tumor progression [63].

\section{Controlling mitochondrial function by modulating intracellular signaling}

Ischemia and reperfusion cannot be avoided during organ transplantation and initiate a cascade of events, which results in tissue damage. While advances in immunosuppressive therapy, amelioration of surgical techniques and organ preservation have significantly improved success rates of solid organ transplantation, IRI remains a major problem requiring substantial follow up treatment [6466].

Massive mitochondrial ROS production during reperfusion paralleled by the depletion of scavengers like superoxide dismutase (SOD), vitamins $\mathrm{C}$ and $\mathrm{E}$ etc. results in the deterioration of organ function or even organ loss [67-69]. There is also evidence that crucial events leading to ROS production already occur during ischemia [70]. Nevertheless, the major hit to the oxygen-deprived cell happens, paradoxically, during reperfusion. The reperfused cells experience an "oxidative burst" with mitochondria-derived superoxide radicals $[71,72]$. Mitochondria are especially sensitive to ROS induced damage and as a consequence disruption of oxidative phosphorylation can be observed culminating in significant reduction of ATP levels, excessive entry of $\mathrm{Ca}^{2+}$ into mitochondria and loss of mitochondrial membrane potential $[73,74]$, resulting in cytosolic release of apoptosis inducing factors, such as apoptosis inducing factor (AIF), cytochrome $c$ and Smac/ DIABLO $[75,76]$.

Attempts to limit ischemia/reperfusion-associated cellular damage have to take into account the important role of mitochondria in this process. Current strategies try to limit the extent of ROS damage by applying anti-oxidants. Much more desirable would be an approach, which avoids oxidative damage by preventing ROS production or scavenging oxygen radicals at the site of their production. First evidence for the control of mitochondrial events by cellular signaling pathways was provided by demonstrating their effect on the expression and function of anti-apoptotic proteins of the Bcl-2 or IAP family [77]. Additional support came from the suggested localization of many diverse signaling molecules (kinases, transcription factors, etc.) to various sites in the mitochondria $[4,78]$. More difficult was the search for targets regulated by them due to experimental difficulties. Candidate processes controlled through signaling include protein and $\mathrm{Ca}^{2+}$ trafficking, oxidative phosphorylation and production of reactive oxygen species. A critical event in cell death initiation is the translocation of the pro-apoptotic Bcl-2 protein BAX to the mitochondria $[79,80]$. Cessation of survival signals, which is a common stimulus for cell death induction, will result in the shut-down of signaling cascades, and in particular the kinases, which compose them. Since phosphorylation may both positively and 

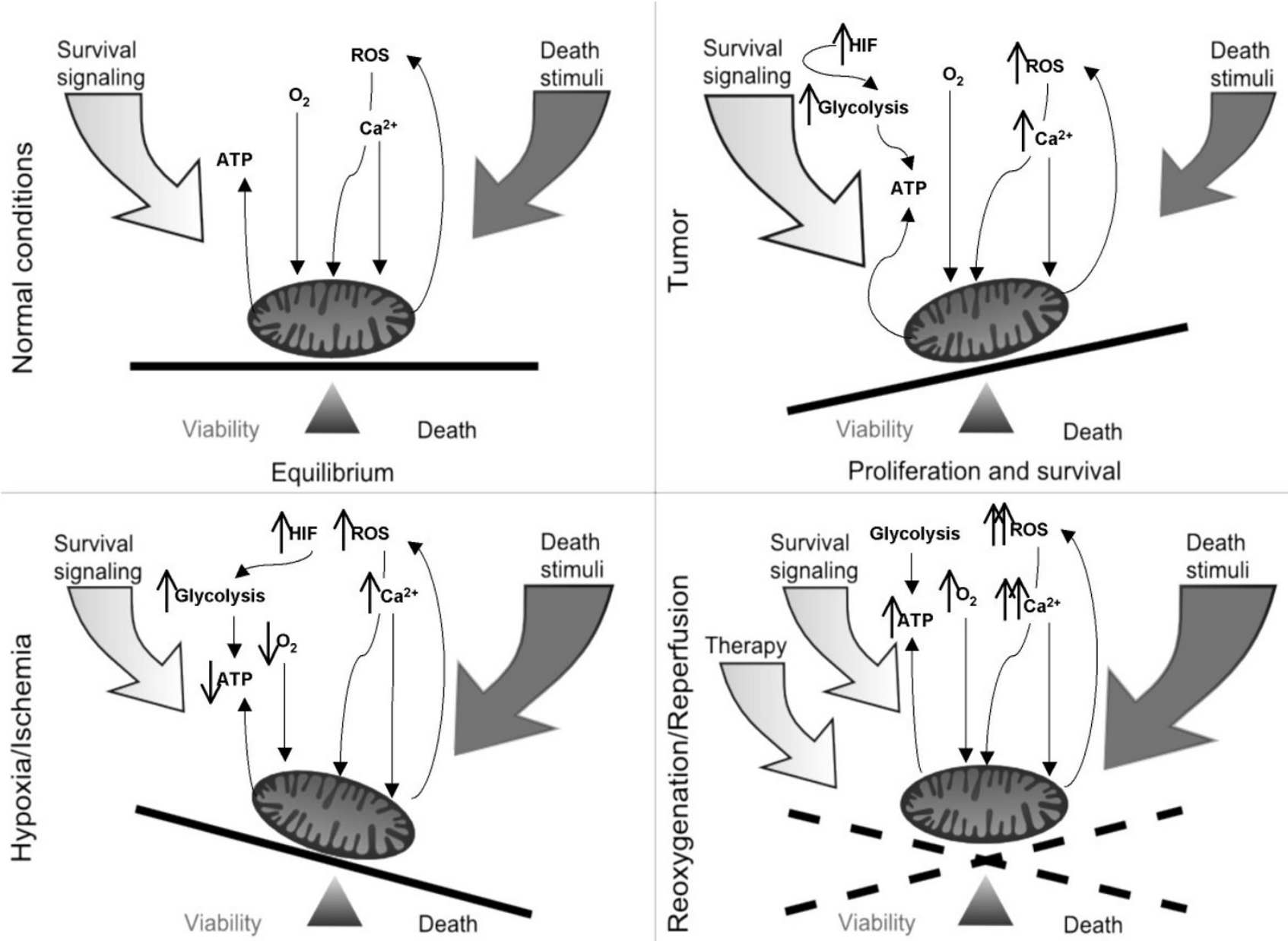

Stress

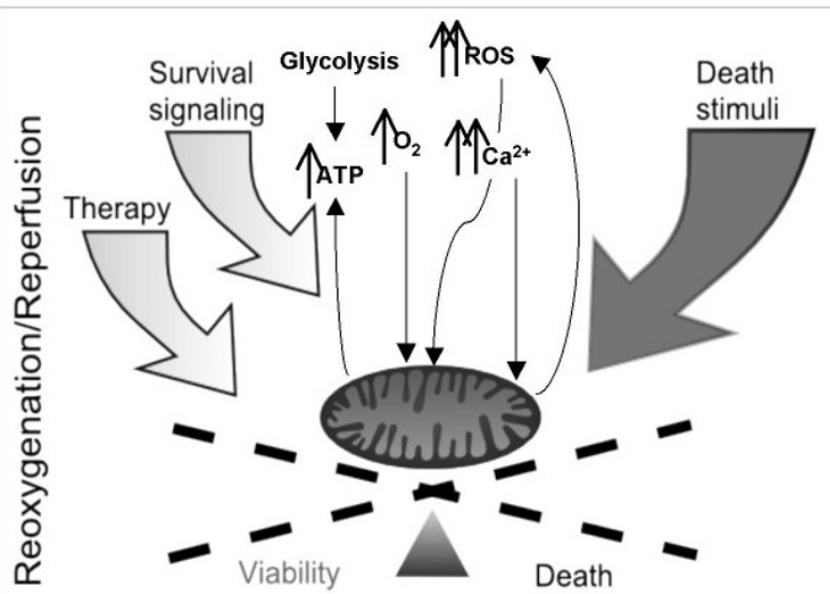

Decision between life and death

Figure I

Mitochondrial rheostat of cell survival control. Key players in the regulation of mitochondrial function are depicted under four different states. Intracellular signaling is represented by bold arrows, filled light grey for survival or dark grey for pro-apoptotic signaling. Under normal conditions cells tolerate a certain level of stress before strong pro-apoptotic stimuli eventually perturb cellular homeostasis. A tumor cell no longer is in a state of equilibrium as ROS levels usually are high, survival signals are enhanced and extra-mitochondrial energy production may become predominant. During ischemia/hypoxia oxidative phosphorylation is disturbed leading to a decrease in ATP. Additionally, cells suffer from elevated ROS and $\mathrm{Ca}^{2+}$ levels. During reperfusion/reoxygenation mitochondrial ROS and $\mathrm{Ca}^{2+}$ levels peak and cell death may follow. Various intracellular signaling pathways are activated during this time and may positively or negatively control mitochondrial function. Eventually, a therapy that abolishes pro-apoptotic signals or elicits survival signaling may help to prevent or limit damage occurring under these conditions.

negatively regulate protein function, signal interruption also will cause the generation of new signals. One of them originates from GSK-3, which upon activation will cause the phosphorylation-dependent ubiquitination and subsequent degradation of the survival protein Mcl-1, which normally negatively controls BAX, followed by its mitochondrial translocation [81]. In our work we recently demonstrated that expression of oncogenic or wild type RAF prevented mitochondrial ROS production, $\mathrm{Ca}^{2+}$ overload and apoptosis [82]. Protein kinase A (PKA) has been implicated in the activation of the NADH-ubiquinone oxidoreductase activity of complex I resulting in reduced ROS production $[83,84]$. Decreased mitochondrial ROS levels were also observed in the heart of transgenic mice expressing the p38 MAPK activator MAPK kinase 6 (MKK6) [85]. Also the tumor suppressor p53 can control ROS levels through its transcriptional target TIGAR [86], leading to an increase in the levels of glutathione (GSH), which scavenges ROS. In contrast, increased mitochondrial ROS production has been described for SHC $[87,88]$. 
A fraction of p66 (SHC) exists within mitochondria, where it oxidizes cytochrome $c$ to form hydrogen peroxide, which in turn induces mitochondrial permeability and apoptosis. Taken together these examples demonstrate that key mitochondrial processes can be subject to the regulation by signaling pathways, which normally respond to extrinsic stimuli (Figure 1). Many of the signaling molecules have attracted considerable interest in the past because of their role in diverse pathological settings including autoimmune diseases, inflammation or cancer. Various approaches have been developed to target them for therapeutic purposes including the development of small molecular weight inhibitors. This raises the possibility of planned pre-emptive intervention to also limit the extent of IRI.

Production of mitochondrial ROS is not only restricted to IR but indeed may be an important intermediate in intrinsic and extrinsic (cell death receptor-dependent) pathways of cell death induction. Thus growth factor abrogation $[82,83]$, death induction through activation of the TNF- $\alpha$ receptor $[89,90]$ or genotoxic stress $[91,92]$ all are linked to the induction of massive ROS production, which is essential for cell death.

\section{Conclusion}

Mitochondria long have been recognized for their role as powerhouse of the cell. Interest in mitochondria was greatly rekindled upon recognition of their central role in regulation of cell death. Many death stimuli converge on these organelles to cause release of apoptogenic factors. This mitochondrial response is also coupled to the interruption of energy production and a collapse of mitochondria $\mathrm{ROS}$ and $\mathrm{Ca}^{2+}$ homeostasis. However, the latter processes may also be directly targeted by pro- and antiapoptotic signaling pathways (Figure 1) opening up possible novel options for therapeutic interference at an early stage, before through the release of second messenger like ROS the damage to cells and organs is amplified.

\section{Competing interests}

The authors declare that they have no competing interests.

\section{Authors' contributions}

JT planned the review outline, drafted the final version. All the other authors equally contributed to the writing of the review.

\section{Acknowledgements}

The authors acknowledge the excellent secretarial assistance provided by Ruth Baldauf in the preparation of the manuscript. Financial support for this work has been provided over the last years by DFG, FWF, MFF (Medizinischer Forschungsfonds Tirol), the TWF (Tiroler Wissenschaftsfonds), Uniqa Versicherungen AG and the Tiroler Krebshilfe.

\section{References}

I. Budinger GR, Duranteau J, Chandel NS, Schumacker PT: Hibernation during hypoxia in cardiomyocytes. Role of mitochondria as the 02 sensor. J Biol Chem 1998, 273(6):3320-3326.

2. Hochachka PW, Buck LT, Doll CJ, Land SC: Unifying theory of hypoxia tolerance: molecular/metabolic defense and rescue mechanisms for surviving oxygen lack. Proc Natl Acad Sci U S A 1996, 93( ( 8):9493-9498.

3. Otani $\mathrm{H}$ : Ischemic preconditioning: from molecular mechanisms to therapeutic opportunities. Antioxid Redox Signal 2008, I0(2):207-247.

4. Kuznetsov AV, Janakiraman M, Margreiter R, Troppmair J: Regulating cell survival by controlling cellular energy production: novel functions for ancient signaling pathways? FEBS Lett 2004, 577(I-2): I-4.

5. Frey TG, Mannella CA: The internal structure of mitochondria. Trends Biochem Sci 2000, 25(7):319-324.

6. Detmer SA, Chan DC: Functions and dysfunctions of mitochondrial dynamics. Nat Rev Mol Cell Biol 2007, 8(I I ):870-879.

7. Hollenbeck PJ, Saxton WM: The axonal transport of mitochondria. J Cell Sci 2005, I I 8(Pt 23):54 | I-54| 9.

8. Fehrenbacher KL, Yang HC, Gay AC, Huckaba TM, Pon LA: Live cell imaging of mitochondrial movement along actin cables in budding yeast. Curr Biol 2004, I 4(22): 1996-2004.

9. Simon VR, Swayne TC, Pon LA: Actin-dependent mitochondrial motility in mitotic yeast and cell-free systems: identification of a motor activity on the mitochondrial surface. I Cell Biol 1995, I30(2):345-354.

10. Yaffe MP: Dynamic mitochondria. Nat Cell Biol 1999, I(6):EI 49-50.

II. Yaffe MP: The machinery of mitochondrial inheritance and behavior. Science 1999, 283(5407): 1493-1497.

12. Miller KE, Sheetz MP: Axonal mitochondrial transport and potential are correlated. J Cell Sci 2004, I I 7(Pt 13):279I-2804.

13. Hales KG, Fuller MT: Developmentally regulated mitochondrial fusion mediated by a conserved, novel, predicted GTPase. Cell 1997, 90(1):I2I-129.

14. Rojo M, Legros F, Chateau D, Lombes A: Membrane topology and mitochondrial targeting of mitofusins, ubiquitous mammalian homologs of the transmembrane GTPase Fzo. J Cell Sci 2002, II 5(Pt 8): 1663-1674.

15. Chen H, Detmer SA, Ewald AJ, Griffin EE, Fraser SE, Chan DC: Mitofusins MfnI and Mfn2 coordinately regulate mitochondrial fusion and are essential for embryonic development. JCell Biol 2003, 160(2):189-200.

16. Pich S, Bach D, Briones P, Liesa M, Camps M, Testar X, Palacin M, Zorzano A: The Charcot-Marie-Tooth type 2A gene product, Mfn2, up-regulates fuel oxidation through expression of OXPHOS system. Hum Mol Genet 2005, I 4(II): | 405- I4I5.

17. Smirnova E, Griparic L, Shurland DL, van der Bliek AM: Dynaminrelated protein Drp I is required for mitochondrial division in mammalian cells. Mol Biol Cell 200I, I 2(8):2245-2256.

18. Nakamura N, Kimura Y, Tokuda M, Honda S, Hirose S: MARCH-V is a novel mitofusin 2- and Drpl-binding protein able to change mitochondrial morphology. EMBO Rep 2006, 7(10): 1019-1022.

19. Wasiak S, Zunino R, McBride HM: Bax/Bak promote sumoylation of DRPI and its stable association with mitochondria during apoptotic cell death. JCell Biol 2007, 177(3):439-450.

20. Alexander C, Votruba M, Pesch UE, Thiselton DL, Mayer S, Moore A, Rodriguez M, Kellner U, Leo-Kottler B, Auburger G, Bhattacharya SS, Wissinger B: OPAI, encoding a dynamin-related GTPase, is mutated in autosomal dominant optic atrophy linked to chromosome 3q28. Nat Genet 2000, 26(2):2II-2I5.

21. Zuchner S, Mersiyanova IV, Muglia M, Bissar-Tadmouri N, Rochelle J, Dadali EL, Zappia M, Nelis E, Patitucci A, Senderek J, Parman Y, Evgrafov O, Jonghe PD, Takahashi Y, Tsuji S, Pericak-Vance MA, Quattrone A, Battaloglu E, Polyakov AV, Timmerman V, Schroder JM, Vance JM: Mutations in the mitochondrial GTPase mitofusin 2 cause Charcot-Marie-Tooth neuropathy type 2A. Nat Genet 2004, 36(5):449-45I.

22. Taylor CT: Mitochondria and cellular oxygen sensing in the HIF pathway. Biochem/ 2008, 409(I): 19-26.

23. Gray MW, Burger G, Lang BF: Mitochondrial evolution. Science 1999, 283(5407): | 476- | $48 \mid$. 
24. Guzy RD, Schumacker PT: Oxygen sensing by mitochondria at complex III: the paradox of increased reactive oxygen species during hypoxia. Exp Physiol 2006, 9 I (5):807-819.

25. Guzy RD, Hoyos B, Robin E, Chen H, Liu L, Mansfield KD, Simon MC, Hammerling $U$, Schumacker PT: Mitochondrial complex III is required for hypoxia-induced ROS production and cellular oxygen sensing. Cell Metab 2005, I(6):40I-408.

26. Kudin AP, Bimpong-Buta NY, Vielhaber S, Elger CE, Kunz WS: Characterization of superoxide-producing sites in isolated brain mitochondria. J Biol Chem 2004, 279(6):4|27-4| 35.

27. Lambert AJ, Brand MD: Inhibitors of the quinone-binding site allow rapid superoxide production from mitochondrial NADH:ubiquinone oxidoreductase (complex I). J Biol Chem 2004, 279(38):394|4-39420.

28. Liu Y, Fiskum G, Schubert D: Generation of reactive oxygen species by the mitochondrial electron transport chain. J Neurochem 2002, 80(5):780-787.

29. Semenza GL: Oxygen-dependent regulation of mitochondrial respiration by hypoxia-inducible factor I. Biochem J 2007, 405(1):1-9.

30. Jager S, Handschin C, St-Pierre J, Spiegelman BM: AMP-activated protein kinase (AMPK) action in skeletal muscle via direct phosphorylation of PGC-I alpha. Proc Natl Acad Sci U S A 2007, 104(29): I $2017-12022$.

31. Zong H, Ren JM, Young LH, Pypaert M, Mu J, Birnbaum MJ, Shulman GI: AMP kinase is required for mitochondrial biogenesis in skeletal muscle in response to chronic energy deprivation. Proc Natl Acad Sci U S A 2002, 99(25): 15983- I5987.

32. Bergeron R, Ren JM, Cadman KS, Moore IK, Perret P, Pypaert M, Young LH, Semenkovich CF, Shulman GI: Chronic activation of AMP kinase results in NRF-I activation and mitochondrial biogenesis. Am J Physiol Endocrinol Metab 200I, 28 I(6):EI340-6.

33. Wallace DC: Mitochondrial diseases in man and mouse. Science 1999, 283(5407): |482-1488.

34. Hardie DG, Hawley SA, Scott JW: AMP-activated protein kinase-development of the energy sensor concept. J Physiol 2006 , 574(Pt I):7-I5

35. Woods A, Dickerson K, Heath R, Hong SP, Momcilovic M, Johnstone SR, Carlson M, Carling D: Ca2+/calmodulin-dependent protein kinase kinase-beta acts upstream of AMP-activated protein kinase in mammalian cells. Cell Metab 2005, 2(I):2I-33.

36. Woods A, Vertommen D, Neumann D, Turk R, Bayliss J, Schlattner $\mathrm{U}$, Wallimann T, Carling D, Rider MH: Identification of phosphorylation sites in AMP-activated protein kinase (AMPK) for upstream AMPK kinases and study of their roles by sitedirected mutagenesis. J Biol Chem 2003, 278(3 I):28434-28442.

37. Carling D: The AMP-activated protein kinase cascade--a unifying system for energy control. Trends Biochem Sci 2004, 29(I): $18-24$

38. Hardie DG, Sakamoto K: AMPK: a key sensor of fuel and energy status in skeletal muscle. Physiology (Bethesda) 2006, 21:48-60

39. Marsin AS, Bertrand L, Rider MH, Deprez J, Beauloye C, Vincent MF, Van den Berghe G, Carling D, Hue L: Phosphorylation and activation of heart PFK-2 by AMPK has a role in the stimulation of glycolysis during ischaemia. Curr Biol 2000, I0(20): 1247-। 255.

40. Zou MH, Hou XY, Shi CM, Kirkpatick S, Liu F, Goldman MH, Cohen RA: Activation of 5'-AMP-activated kinase is mediated through c-Src and phosphoinositide 3-kinase activity during hypoxia-reoxygenation of bovine aortic endothelial cells. Role of peroxynitrite. J Biol Chem 2003, 278(36):34003-340I0.

4I. Hue L, Rider MH: The AMP-activated protein kinase: more than an energy sensor. Essays Biochem 2007, 43:12I-I37.

42. Horman S, Browne G, Krause U, Patel J, Vertommen D, Bertrand L, Lavoinne A, Hue L, Proud C, Rider M: Activation of AMP-activated protein kinase leads to the phosphorylation of elongation factor 2 and an inhibition of protein synthesis. Curr Biol 2002, I 2(16): 1419-1423.

43. Bolster DR, Crozier SJ, Kimball SR, Jefferson LS: AMP-activated protein kinase suppresses protein synthesis in rat skeletal muscle through down-regulated mammalian target of rapamycin (mTOR) signaling. J Biol Chem 2002, 277(27):23977-23980.

44. Kimura N, Tokunaga C, Dalal S, Richardson C, Yoshino K, Hara K Kemp BE, Witters LA, Mimura O, Yonezawa K: A possible linkage between AMP-activated protein kinase (AMPK) and mam- malian target of rapamycin (mTOR) signalling pathway. Genes Cells 2003, 8(I):65-79.

45. Inoki K, Zhu T, Guan KL: TSC2 mediates cellular energy response to control cell growth and survival. Cell 2003, I I5(5):577-590.

46. Gwinn DM, Shackelford DB, Egan DF, Mihaylova MM, Mery A, Vasquez DS, Turk BE, Shaw RJ: AMPK phosphorylation of raptor mediates a metabolic checkpoint. Mol Cell 2008, 30(2):2। 4-226.

47. Kurth-Kraczek EJ, Hirshman MF, Goodyear LJ, Winder WW: 5 AMP-activated protein kinase activation causes GLUT4 translocation in skeletal muscle. Diabetes 1999, 48(8): |667-|67|.

48. Treebak JT, Glund S, Deshmukh A, Klein DK, Long YC, Jensen TE, Jorgensen SB, Viollet B, Andersson L, Neumann D, Wallimann T, Richter EA, Chibalin AV, Zierath JR, Wojtaszewski JF: AMPK-mediated ASI 60 phosphorylation in skeletal muscle is dependent on AMPK catalytic and regulatory subunits. Diabetes 2006, 55(7):205I-2058.

49. Holmes BF, Kurth-Kraczek EJ, Winder WW: Chronic activation of 5 '-AMP-activated protein kinase increases GLUT-4, hexokinase, and glycogen in muscle. I Appl Physiol 1999, 87(5): 1990-1995.

50. Zheng D, MacLean PS, Pohnert SC, Knight JB, Olson AL, Winder WW, Dohm GL: Regulation of muscle GLUT-4 transcription by AMP-activated protein kinase. J Appl Physiol 200I, 9I(3): 1073-I083

5I. Saks V, Favier R, Guzun R, Schlattner U, Wallimann T: Molecular system bioenergetics: regulation of substrate supply in response to heart energy demands. J Physiol 2006, 577(Pt 3):769-777.

52. Hayashi T, Hirshman MF, Fujii N, Habinowski SA, Witters LA, Goodyear LJ: Metabolic stress and altered glucose transport: activation of AMP-activated protein kinase as a unifying coupling mechanism. Diabetes 2000, 49(4):527-53I.

53. Bergeron R, Previs SF, Cline GW, Perret P, Russell RR 3rd, Young LH, Shulman Gl: Effect of 5-aminoimidazole-4-carboxamide-Ibeta-D-ribofuranoside infusion on in vivo glucose and lipid metabolism in lean and obese Zucker rats. Diabetes 200I, 50(5): $1076-1082$

54. Russell RR 3rd, Bergeron R, Shulman GI, Young LH: Translocation of myocardial GLUT-4 and increased glucose uptake through activation of AMPK by AICAR. Am J Physiol 1999, 277(2 Pt 2):H643-9.

55. Wu Z, Puigserver P, Andersson U, Zhang C, Adelmant G, Mootha V, Troy A, Cinti S, Lowell B, Scarpulla RC, Spiegelman BM: Mechanisms controlling mitochondrial biogenesis and respiration through the thermogenic coactivator PGC-I. Cell 1999, 98(I): II5-I24.

56. Cai Y, Martens GA, Hinke SA, Heimberg H, Pipeleers D, Van de Casteele M: Increased oxygen radical formation and mitochondrial dysfunction mediate beta cell apoptosis under conditions of AMP-activated protein kinase stimulation. Free Radic Biol Med 2007, 42(I):64-78.

57. Zou MH, Kirkpatrick SS, Davis BJ, Nelson JS, Wiles WG, Schlattner U, Neumann D, Brownlee M, Freeman MB, Goldman MH: Activation of the AMP-activated protein kinase by the anti-diabetic drug metformin in vivo. Role of mitochondrial reactive nitrogen species. J Biol Chem 2004, 279(42):43940-4395 I.

58. Dang CV, Semenza GL: Oncogenic alterations of metabolism. Trends Biochem Sci 1999, 24(2):68-72.

59. Kroemer G, Pouyssegur J: Tumor cell metabolism: cancer's Achilles' heel. Cancer Cell 2008, I3(6):472-482.

60. Kuznetsov AV, Mayboroda O, Kunz D, Winkler K, Schubert W, Kunz WS: Functional imaging of mitochondria in saponin-permeabilized mice muscle fibers. J Cell Biol I998, | 40(5): I09|-1099.

6I. Gottlieb E, Tomlinson IP: Mitochondrial tumour suppressors: a genetic and biochemical update. Nat Rev Cancer 2005, 5(I I):857-866

62. King A, Selak MA, Gottlieb E: Succinate dehydrogenase and fumarate hydratase: linking mitochondrial dysfunction and cancer. Oncogene 2006, 25(34):4675-4682.

63. Brandon M, Baldi P, Wallace DC: Mitochondrial mutations in cancer. Oncogene 2006, 25(34):4647-4662.

64. Perico N, Cattaneo D, Sayegh MH, Remuzzi G: Delayed graft function in kidney transplantation. Lancet 2004, 364(9447): $1814-1827$. 
65. McLaren AJ, Jassem W, Gray DW, Fuggle SV, Welsh KI, Morris PJ: Delayed graft function: risk factors and the relative effects of early function and acute rejection on long-term survival in cadaveric renal transplantation. Clin Transplant 1999, 13(3):266-272.

66. Deschênes M, Belle SH, Krom RA, Zetterman RK, Lake JR: Early allograft dysfunction after liver transplantation: a definition and predictors of outcome. National Institute of Diabetes and Digestive and Kidney Diseases Liver Transplantation Database. Transplantation 1998, 66(3):302-310.

67. Victor VM, Rocha M: Targeting antioxidants to mitochondria: a potential new therapeutic strategy for cardiovascular diseases. Curr Pharm Des 2007, I 3(8):845-863.

68. Cruthirds DL, Novak L, Akhi KM, Sanders PW, Thompson JA, MacMillan-Crow LA: Mitochondrial targets of oxidative stress during renal ischemia/reperfusion. Arch Biochem Biophys 2003, 4I2(I):27-33.

69. Maglione M, Hermann M, Hengster P, Schneeberger S, Mark W, Obrist P, Werner-Felmayer G, Werner ER, Margreiter R, Brandacher G: Tetrahydrobiopterin attenuates microvascular reperfusion injury following murine pancreas transplantation. Am J Transplant 2006, 6(7): I55I-I559.

70. Chen Q, Moghaddas S, Hoppel CL, Lesnefsky Ej: Ischemic defects in the electron transport chain increase the production of reactive oxygen species from isolated rat heart mitochondria. Am J Physiol Cell Physiol 2008, 294(2):C460-6.

71. Jassem W, Fuggle SV, Rela M, Koo DD, Heaton ND: The role of mitochondria in ischemia/reperfusion injury. Transplantation 2002, 73(4):493-499.

72. Milagros Rocha M, Victor VM: Targeting antioxidants to mitochondria and cardiovascular diseases: the effects of mitoquinone. Med Sci Monit 2007, I3(7):RAI32-45.

73. Brookes PS, Yoon Y, Robotham JL, Anders MW, Sheu SS: Calcium, ATP, and ROS: a mitochondrial love-hate triangle. Am J Physiol Cell Physiol 2004, 287(4):C8I7-33.

74. Christophe M, Nicolas S: Mitochondria: a target for neuroprotective interventions in cerebral ischemia-reperfusion. Curr Pharm Des 2006, I 2(6):739-757.

75. Martinou JC, Green DR: Breaking the mitochondrial barrier. Nat Rev Mol Cell Biol 200I, 2(I):63-67.

76. Ravagnan L, Roumier T, Kroemer G: Mitochondria, the killer organelles and their weapons. I Cell Physiol 2002, 192(2): $131-137$.

77. Troppmair J, Rapp UR: Raf and the road to cell survival: a tale of bad spells, ring bearers and detours. Biochem Pharmacol 2003 , 66(8): $134|-| 345$.

78. Huttemann M, Lee I, Samavati L, Yu H, Doan JW: Regulation of mitochondrial oxidative phosphorylation through cell signaling. Biochim Biophys Acta 2007, I 773(1 2): 1701-1720.

79. Chipuk JE, Green DR: How do BCL-2 proteins induce mitochondrial outer membrane permeabilization? Trends Cell Biol 2008, 18(4): $157-164$.

80. Meier $P$, Vousden $\mathrm{KH}$ : Lucifer's labyrinth--ten years of path finding in cell death. Mol Cell 2007, 28(5):746-754.

8I. Maurer U, Charvet C, Wagman AS, Dejardin E, Green DR: Glycogen synthase kinase-3 regulates mitochondrial outer membrane permeabilization and apoptosis by destabilization of MCL-I. Mol Cell 2006, 2 I(6):749-760.

82. Kuznetsov AV, Smigelskaite J, Doblander C, Janakiraman M, Hermann M, Wurm M, Scheidl SF, Sucher R, Deutschmann A, Troppmair J: Survival signaling by C-RAF: mitochondrial reactive oxygen species and Ca2+ are critical targets. Mol Cell Biol 2008, 28(7):2304-2313.

83. Piccoli C, Scacco S, Bellomo F, Signorile A, luso A, Boffoli D, Scrima $R$, Capitanio N, Papa S: cAMP controls oxygen metabolism in mammalian cells. FEBS Lett 2006, 580( ( 8):4539-4543.

84. Papa S, De Rasmo D, Scacco S, Signorile A, Technikova-Dobrova Z Palmisano G, Sardanelli AM, Papa F, Panelli D, Scaringi R, Santeramo A: Mammalian complex I: A regulable and vulnerable pacemaker in mitochondrial respiratory function. Biochim Biophys Acta 2008.

85. Wall JA, Wei J, Ly M, Belmont P, Martindale JJ, Tran D, Sun J, Chen WJ, Yu W, Oeller P, Briggs S, Gustafsson AB, Sayen MR, Gottlieb RA, Glembotski CC: Alterations in oxidative phosphorylation complex proteins in the hearts of transgenic mice that over- express the p38 MAP kinase activator, MAP kinase kinase 6. Am J Physiol Heart Circ Physiol 2006, 29 I (5): H2462-72.

86. Bensaad K, Tsuruta A, Selak MA, Vidal MN, Nakano K, Bartrons R, Gottlieb E, Vousden KH: TIGAR, a p53-inducible regulator of glycolysis and apoptosis. Cell 2006, I 26(I): 107-120.

87. Migliaccio E, Giorgio M, Pelicci PG: Apoptosis and aging: role of p66Shc redox protein. Antioxid Redox Signal 2006, 8(3-4):600-608.

88. Giorgio M, Migliaccio E, Orsini F, Paolucci D, Moroni M, Contursi C, Pelliccia G, Luzi L, Minucci S, Marcaccio M, Pinton P, Rizzuto R, Bernardi P, Paolucci F, Pelicci PG: Electron transfer between cytochrome $\mathrm{c}$ and $\mathrm{p} 66 \mathrm{Sh} \mathrm{h}$ generates reactive oxygen species that trigger mitochondrial apoptosis. Cell 2005, I 22(2):22I-233.

89. Kamata H, Honda S, Maeda S, Chang L, Hirata H, Karin M: Reactive oxygen species promote TNFalpha-induced death and sustained JNK activation by inhibiting MAP kinase phosphatases. Cell 2005, I 20(5):649-66I.

90. Temkin V, Karin M: From death receptor to reactive oxygen species and c-Jun $\mathbf{N}$-terminal protein kinase: the receptorinteracting protein I odyssey. Immunol $\operatorname{Rev} 2007,220: 8-21$.

9I. Valko M, Leibfritz D, Moncol J, Cronin MT, Mazur M, Telser J: Free radicals and antioxidants in normal physiological functions and human disease. Int J Biochem Cell Biol 2007, 39(I):44-84.

92. Bertram C, Hass R: Cellular responses to reactive oxygen species-induced DNA damage and aging. Biol Chem 2008, 389(3):2II-220.

Publish with Bio Med Central and every scientist can read your work free of charge

"BioMed Central will be the most significant development for disseminating the results of biomedical research in our lifetime. "

Sir Paul Nurse, Cancer Research UK

Your research papers will be:

- available free of charge to the entire biomedical community

- peer reviewed and published immediately upon acceptance

- cited in PubMed and archived on PubMed Central

- yours - you keep the copyright 